\title{
EL DESPIDO INDIRECTO Y EL NUEVO PROCEDIMIENTO DE TUTELA DE DERECHOS FUNDAMENTALES DEL TRABAJADOR
}

\author{
GABRIELA LANATA FUENZALIDA* \\ Universidad de Concepción
}

RESUMEN: El despido indirecto o autodespido es una institución reconocida en nuestro Código del Trabajo y que le permite al trabajador poner término a la relación laboral, cuando han mediado determinados incumplimientos por parte del empleador. No obstante su gran importancia, fue dejado al margen o ignorado al estudiarse la reforma procesal recientemente instaurada en la materia, lo que no ha estado exento de problemas. Este artículo analiza, específicamente, la relación entre este instituto y el procedimiento de tutela, desde un prisma esencialmente positivista.

Palabras clave: Despido indirecto, autodespido, derechos fundamentales, proceso laboral, procedimiento de tutela.

ABSTRACT: The indirect dismissal o self-dismissal is a recognized institution in our Labor Code and allows worker to terminate the employment relationship, when the employer neglects. But despite its great importance, it was left out or ignored when studying the recent procedural reforms instituted in the matter, which has not been without problems. This paper examines specifically the relation between the institute and the tutelage proceeding from an essentially positivist prism.

Key words: Indirect dismissal, self dismissal, fundamental rights, labor law process, tutelage procedure.

\section{INTRODUCCIÓN}

En esta materia tiene trascendental importancia el tipo de contenido obligacional que se genera en un contrato de trabajo lo que, por cierto, no le quita su carácter contractual. Como señala el autor Caparrós, para analizar las obligaciones que rigen la relación laboral debe tenerse en claro qué es lo que se pone en juego en esta clase de vínculos ${ }^{1}$. Parece ser que la doctrina que se ha divulgado en mayor medida en nuestro sistema es la germánica, que junto a la relación de trabajo servil, por medio del cual un hombre libre se ponía al servicio de otro que le concedía a cambio protección, ayuda y representación. Pero a la vez, este contrato, hacía surgir un vínculo personal de fidelidad recíproca, que se emparentaba con los vínculos familiares, y se hacía participar a quienes se unían por medio de él en una misma comunidad de derechos y deberes ${ }^{2}$.

Consecuentemente con lo dicho, el contrato de trabajo se estructura como un actocondición, que genera la aplicación de un estatuto insoslayable, que determina la protección

\footnotetext{
* Abogada. Licenciada en Ciencias Jurídicas Universidad de Concepción. Magíster en Educación, Universidad de Concepción. Magíster en Derecho Privado Universidad Nacional de Rosario. Profesora de Derecho del Trabajo y de la Seguridad Social, Facultad de Derecho, Universidad de Concepción.

1 CAPArrós, Fernando, "Obligaciones de las partes". En: ACKerman, Mario E., Tratado de Derecho del Trabajo. Tomo III. Buenos Aires, Argentina: Rubinzal Culzoni Editores, 2005, p. 9

2 Ibid., p. 10., citando a SuPIOT, Alian, Crítica del derecho del Trabajo. Informes y Estudios del Ministerio del Trabajo y Asuntos Sociales. Madrid, España, 1996, pp. 29 y ss.
} 
misma que es la base de todo el Derecho del Trabajo. Este estatuto puede emanar de fuentes de diferente naturaleza, tales como leyes, estatutos particulares, convenios colectivos, reglamentos internos de la empresa, por nombrar los más comunes. De allí emanan, quiéranlo o no las partes, los derechos y deberes propios del contrato de trabajo, entre los cuales no solamente se encuentran aquellos que dicen relación con determinadas prestaciones, de suyo importantes, pero no las únicas, tema que ha llevado a los autores a diferenciar entre los deberes de prestación, designando a aquellos que se traducen en dar o hacer determinadas acciones propias y esenciales del contrato, como trabajar y pagar las remuneraciones y los deberes de conducta, que designa a aquellos en los que está comprometido el comportamiento del hombre como tal, y que se refiere a la forma de dar cumplimiento a todas y cada una de las obligaciones que emanan de la relación laboral, y cualquiera que sea su fuente de origen. Se extienden, según la doctrina moderna, desde la etapa precontractual y hasta el momento mismo de la extinción de la relación laboral ${ }^{3}$. A modo de referencia en tal sentido puede citarse el artículo 242, de la Ley de Contrato de Trabajo argentina, que dispone que exige justa causa para efectuar la denuncia del contrato de trabajo en caso de inobservancia por parte de la otra de las obligaciones resultantes del mismo que configuren injuria y que, por su gravedad, no consienta la prosecución de la relación, dejando su valoración entregada, prudencialmente, a los jueces, "teniendo en consideración el carácter de las relaciones que resulta de un contrato de trabajo, según lo dispuesto en la presente ley, y las modalidades y circunstancias personales en cada caso". Ya más en concreto, puede considerarse que el trabajador goza de una especie de derecho a la estabilidad, de mayor o menor intensidad, según sea la respectiva legislación, el que se entiende, en todo caso, como "el derecho o protección jurídica que garantiza la permanencia del trabajador en el empleo, teniendo en cuenta que esta garantía de permanencia o estabilidad es un bien jurídico protegido atento a las necesidades de ser humano de trabajador" ". Se trata de un derecho, pero nada le impide decidir su término, especialmente cuando el empleador incumple gravemente con sus obligaciones, sean de prestación o de conducta.

\section{EL DESPIDO INDIRECTO}

\subsection{LA SITUACIÓN PREVIA AL NUEVO PROCEDIMIENTO}

La idea de que el trabajador al incorporarse a la empresa sigue teniendo la calidad de ser humano y, como tal, goza de derechos fundamentales que se denominaron inespecíficos, tuvo importante reconocimiento sustantivo en nuestro Código del Trabajo, el que no fue acompañado de la misma forma por la protección procesal o adjetiva, de tal manera que el despido indirecto, en la práctica, fue considerado como una forma de autotutela del trabajador que, aun cuando limitada, le permitía alejarse de la organización empresarial, cuando era objeto de ciertos abusos, obteniendo el pago de algunas indemnizaciones. En efecto, la tendencia de la legislación laboral, previa al establecimiento del procedimiento de tutela,

\footnotetext{
3 En este sentido, CAPARRós, Fernando, op. cit. (n. 1), p. 12.

4 Tosca, Diego y Dragan Gigena, José Ignacio, "Estabilidad en el empleo". En: ACKerman, Mario E., Extinción de la relación laboral. Buenos Aires, Argentina: Rubinzal Culzoni Editores, 2008, p. 22.
} 
exaltaba de manera un tanto incomprensible el autodespido como mecanismo de protección frente a determinadas vulneraciones a los derechos fundamentales. Así, por ejemplo, después de una larga tramitación se dictó una ley que calificó, expresamente, el acoso sexual como una conducta atentatoria a la dignidad de la persona y si bien estableció un efectivo procedimiento de investigación del mismo, introdujo engorrosas modificaciones al sistema indemnizatorio para el trabajador afectado, premiando al empleador con una disminución considerable de su carga indemnizatoria cuando, habiendo acusado a un trabajador como autor de estas conductas respecto de otro trabajador, después de efectuado el respectivo procedimiento de investigación interna, un juez determina que era inocente. Por otra parte, si el acosador es el propio empleador u otro trabajador y aquel no lo protege como en derecho corresponde, le reconocía la opción del autodespido, aun cuando se introdujeron modificaciones que alteraron su normal aplicación. Así, se estableció que si el empleador no ha cumplido con las reglas de la investigación previa, quedará obligado al pago de las indemnizaciones habituales, esto es, sustitutiva del aviso previo, por años de servicios y sus recargos y las otras indemnizaciones a que tenga derecho. Sin embargo, nada se indicó en relación a lo que ocurre cuando ha cumplido con las reglas de investigación, pudiendo ello llevar a concluir que, en este caso, el trabajador que se ha visto obligado a autodespedirse, porque el empleador ha atentado contra su dignidad al incurrir en conductas de acoso sexual, solo porque se han efectuado las investigaciones pertinentes, se verá privado de sus indemnizaciones, interpretación posible, aunque no comparto. Se demuestran así las inconsecuencias en que se había incurrido al recurrir, cada vez más, al despido indirecto, prácticamente, como único medio de solución laboral a la infracción de derechos fundamentales.

Algo similar ha ocurrido con el proyecto de ley que pretendía o aún pretende regular el acoso moral, en que la solución entregada era aconsejar el autodespido, sin detectar que ello significaba, simplemente, que el acosador había logrado el objetivo de alejar al trabajador de la organización empresarial, anulando de paso su autoestima y produciéndole serios daños a su salud, tanto mental como física ${ }^{5}$. Este proyecto no fue aprobado en esta forma y aún continúa en tramitación en la Cámara de Diputados.

El artículo 171 del Código del Trabajo ${ }^{6}$ confiere al trabajador una posibilidad, un derecho y no una obligación, llamado a ejercerse cuando quien ha incurrido en graves causales de terminación del contrato de trabajo ha sido el empleador y que implica la pérdida de su fuente laboral a cambio del pago de ciertas indemnizaciones. En consecuencia, es factible preguntarse cuál es la posibilidad que se le entrega al trabajador al decidir no ejercer el derecho a poner término del contrato que la ley le da. Negarle la opción de demandar por la indemnización de perjuicios manteniendo la vigencia de la relación laboral, implicaría una situación desmedrada frente a los contratantes sujetos a relaciones jurídicas diferentes, pues se estaría obligando al trabajador, que no desea perder su fuente de trabajo o cuyas indemnizaciones serían de escaso monto dada la antigüedad en la empresa, a soportar incumpli-

\footnotetext{
5 Actualmente existen dos proyectos que buscan esta regulación, 3198-13 y 4815-13. El primero de ellos se inició el 4 de marzo de 2003 y desde el 10 de marzo de 2009 se encuentra en segundo trámite constitucional en el Senado. El segundo, se inició el 19 de diciembre de 2006 y se encuentra en el primer trámite constitucional en el Senado, desde el 9 enero de 2007.

6 En lo sucesivo, cada vez que se cite una disposición sin indicar el código o ley a que pertenece, debe entenderse referido al Código del Trabajo.
} 
mientos indebidos del empleador e, incluso, un trato vejatorio de su parte o de quienes lo representan, echando por tierra la protección a sus derechos fundamentales. La terminación del contrato no podía ser la única posibilidad que la ley le confería al trabajador, máxime si uno de los principios informadores del Derecho del Trabajo es, precisamente, el de la continuidad que, entre sus postulados, aboga por la conservación de la relación laboral, aun después de los incumplimientos que puedan haber existido, lo que se basa en el principio de la estabilidad, reconocido, obviamente, en beneficio del trabajador.

El tema no era solo cuestión de ley. Digno de destacar resulta un fallo dictado por la Corte de Apelaciones de Concepción en una causa seguida por una trabajadora durante el desarrollo de la relación laboral y en una época previa a la iniciación del nuevo proceso. Se trató, en la especie, de una profesional, trabajadora de una universidad y que desempeñaba un cargo directivo en la misma, lo que le daba la calidad de autoridad universitaria. Sin embargo, durante el uso de su descanso de maternidad, la entidad empleadora decidió, simplemente, suprimir el cargo y al término de su licencia maternal no se le proporcionó trabajo, encontrándose con que su oficina e implementos personales habían sido entregados a otro trabajador, que se desempeñaba en el lugar, procediéndose, también, a incumplir con el pago íntegro de sus remuneraciones. La trabajadora, que se encontraba amparada por el fuero maternal, no deseaba renunciar a su trabajo y decidió demandar a fin de obtener la indemnización de los perjuicios ocasionados, entendiendo, al parecer, que el empleador estaba en su derecho de organizar su empresa, pero sin que ello justificara el atentado ocasionado a su honra y dignidad. Estimó que el proceder de la institución empleadora no solo había incurrido en verdaderos incumplimientos contractuales, sino que también había atentado a su dignidad como persona, atentados que provenían de quien estaba obligado a proteger eficazmente su vida, salud e integridad, existiendo nexo causal entre su conducta ilícita culposa, el hecho y el daño.

El juez de primera instancia dejó establecido el hecho de que el cargo de decana que la actora ostentaba hasta el momento de iniciar su descanso prenatal, había desaparecido al momento de crearse una nueva facultad, que se denominó de Ciencias Sociales y que en su reemplazo se ofrecieron a la trabajadora otros cargos que, en el decir de la actora, eran solo decorosos. De lo que se desprende, señaló el juez, "que la demandada incumplió el contrato de trabajo de la actora, al negarle la función para la cual había sido contratada y/o alterar tales funciones, hecho que por lo demás le significó la aplicación de multas por parte de la Inspección Provincial del Trabajo, como consta en los antecedentes remitidos por la entidad administrativa”.

Lo curioso fue, sin embargo, que el magistrado, a continuación, estimó que ante tal incumplimiento todo trabajador:

"dispone de los resguardos legales para proteger sus derechos, es decir, de las acciones correspondientes para dejar sin efecto lo obrado por su empleadora, cuando los cambios exceden de la facultad de dirección del empleador (reclamando conforme al inciso $3^{\circ}$ del artículo 12 del Código del Trabajo) o bien para obtener las indemnizaciones del término de contrato, incluso con incremento, si opta por la figura del despido indirecto contemplado en el artículo 171 del código laboral, instituciones que son 
propias absolutamente del derecho laboral y que constituyen resarcimientos o recompensas originadas en la relación de trabajo que une a las partes".

Y, aún más, agregó que:

"en las normas citadas, se aprecia que el legislador contempló esta posibilidad, regulándola expresamente, resultando incompatible, por ende, que a consecuencia de las decisiones que el empleador adopte en relación con la estructura, funcionamiento $\mathrm{u}$ organización de su industria, que eventualmente pudiera significar a un dependiente el término de su contrato o el cambio en las condiciones en las que este se desarrollaba, se indemnicen perjuicios de índole moral, puesto que no va a ser extraño que el trabajador experimente en mayor o menor grado, cierta aflicción o pesar al perder su fuente laboral, o cambiar drásticamente sus condiciones de trabajo, pero esa aflicción, que es normal, encuentra su compensación en la ley laboral a través de las sanciones o indemnizaciones contenidas en normas indicadas. El daño moral indemnizable, por el contrario, será solo aquel que provenga de actos u omisiones dolosas o culposas del empleador que impliquen faltar a sus deberes de protección para con sus empleados y que causen un perjuicio al trabajador, vale decir un sufrimiento excepcional, derivado de otras fuentes".

Llaman la atención, poderosamente, algunas cuestiones: la primera, que se haya reconocido de manera expresa el incumplimiento contractual del empleador para, acto seguido, justificarlo en aras de la restructuración de la empresa; pero no solamente ello, sino que el tribunal haya estimado que al trabajador afectado (contratante en un contrato bilateral) le estaba vedado pedir indemnización alguna, pues el dolor sufrido "es normal" debiendo limitarse a los caminos que le señalaba la ley, esto es, reclamar por lo que pareció considerar la utilización del ius variandi ${ }^{7}$ u optar por el despido indirecto, es decir, resignarse a perder el trabajo, prefiriendo una indemnización que dependerá, no del daño sufrido, sino de la antigüedad del trabajador en la empresa ${ }^{8}$. Derechamente, estableció que la pretensión de una indemnización por daño moral resultaba incompatible, por considerar que no va a ser extraño que el trabajador experimente, en mayor o menor grado, cierta aflicción o pesar al perder su fuente laboral, o cambiar drásticamente sus condiciones de trabajo, a consecuencia de las decisiones que el empleador adopte en relación con la estructura, funcionamiento u organización de su industria que, eventualmente, pudiera significar a un dependiente el término de su contrato o el cambio en las condiciones en las que este se desarrollaba, pero esa aflicción resulta normal y no indemnizable.

\footnotetext{
El Código del Trabajo en su artículo 12 permite esta posibilidad, de carácter excepcional en materia contractual, al permitirle a uno de los contratantes variar de manera unilateral las condiciones contractuales. Es evidente que, en este caso en particular, escaso éxito podía tener la reclamación, que se efectúa a la Inspección del Trabajo, la que ya había cursado las multas correspondientes a la entidad empleadora. Por otra parte, el propio juez laboral legitimó el proceder de la institución universitaria.

8 Es más, si no contaba con un año de servicios, solo podrá acceder a una indemnización equivalente a un mes de la última indemnización.
} 
Es decir, según el criterio del a quo, si el trabajador quería mantener su fuente laboral debía soportar estoicamente toda aflicción, pena, dolor, resignándose a sufrir daños sin indemnización alguna. Si no deseaba ello, debía hacer uso de la institución del despido indirecto. Esta conclusión estaba en abierta contradicción con la norma legal que, claramente, le daba (y aún le da) al trabajador la opción de utilizar o no la institución. Lo que debía analizarse es qué alternativa le quedaba, si no deseaba autodespedirse, posibilidad que, como ya se ha dicho, le privaba de su fuente de trabajo.

El fallo fue recurrido por la trabajadora. La empleadora, en cambio, no se alzó en contra de la sentencia, entendiendo que no había sufrido agravio al rechazarse la demanda, no obstante que el juez declaró la existencia del incumplimiento contractual. La demandada, por tanto, reconoció tal incumplimiento, adquiriendo, la resolución, el carácter de firme.

La Corte de Apelaciones de Concepción consideró, en cambio, que la utilización del despido indirecto era una posibilidad que la actora pudo ejercer, aun cuando le habría significado, obviamente, la terminación de su contrato de trabajo, pero que, en ningún caso, estaba obligada a hacer uso del mismo. Consideró que el artículo 171 del Código del Trabajo confiere al trabajador una posibilidad, un derecho y no una obligación, llamado a ejercerse cuando quien ha incurrido en graves causales de terminación del contrato de trabajo ha sido el empleador, opción que implica la pérdida de su fuente laboral a cambio del pago de ciertas indemnizaciones. Se sostuvo, en el fallo, que tal decisión la ley la entrega al trabajador, puesto que negarle la posibilidad de demandar indemnización de perjuicios, manteniendo la vigencia de la relación laboral, implicaría obligarlo a soportar incumplimientos indebidos de su contraparte e, incluso, tratos vejatorios, por no perder su fuente de trabajo o no convenirle obtener indemnizaciones que serían de escaso monto, dada la antigüedad en la empresa. En consecuencia, la terminación del contrato no puede ser la única posibilidad que la ley le confiere al trabajador, frente a un incumplimiento del empleador, máxime si uno de los principios informadores del Derecho del Trabajo es, precisamente, el de la continuidad que, entre algunos de sus postulados, aboga por la conservación de la relación laboral, aun después de los incumplimientos que puedan haber existido, lo que se basa en el principio de la estabilidad, reconocido en beneficio del trabajador. El fallo consideró, asimismo, que, tal como había quedado establecido en la sentencia de primera instancia, la actora se encontraba amparada por fuero maternal, circunstancia que hacía más improcedente la conclusión de que el único camino a seguir frente a un incumplimiento patronal, pudiera ser el autodespido, que la obligaba a perder su fuente laboral, estando amparada por normas de carácter especial y de aplicación tan general, como son las de protección a la maternidad. Además, tal conclusión implicaría reconocer que un empleador que desea prescindir ilegalmente de los servicios de un trabajador aforado, podría incurrir intencionalmente en serias irregularidades o incumplimientos del contrato de trabajo, para obligarlo a usar la institución del despido indirecto, optando al pago de una indemnización, cuyo monto dependerá, al fin, de su antigüedad en la empresa, anulando de esta forma la protección que el fuero laboral le otorgaba, y en este caso en particular, vulnerando de manera directa y general todas las normas de protección a la maternidad y, especialmente, la obligación del empleador contemplada en el inciso final del artículo 195 del Código del Trabajo, que lo obligaba a mantenerle el puesto de trabajo o el empleo. 
Finalmente, en el fallo de alzada se consideró que todo lo razonado llevaba a la lógica conclusión de que el autodespido no era el único camino que puede seguir el trabajador frente a un incumplimiento del empleador, conclusión corroborada por la expresión facultativa que la propia ley emplea en el artículo 171, en análisis, al señalar que, si quien incurre en alguna de las causales de terminación de contrato que allí se señalan es el empleador, el trabajador podrá poner término al contrato.

Un aspecto digno de considerar, como también lo dejó establecido el fallo de apelación, es que la misma norma en el inciso $2^{\circ}$, le confiere al trabajador la posibilidad de reclamar, de forma conjunta con las indemnizaciones laborales propias de la terminación del contrato de trabajo, simultáneamente las otras indemnizaciones a que tenga derecho, estableciendo, de manera expresa, su compatibilidad con las indemnizaciones por años de servicios, su recargo y la sustitutiva del aviso previo, tratándose de determinadas causales.

Debe recordarse, sin embargo, que el fallo en comento se dictó antes de la entrada en vigencia de las nuevas normas de procedimiento, que podrían llevar a una conclusión más clara al respecto, según se analizará más adelante.

Por otra parte, además de la compatibilidad enunciada, la redacción de la norma lleva a concluir que estas otras indemnizaciones pueden existir como alternativa a las derivadas de la terminación del contrato. No obstante que el Código del Trabajo nada dice sobre cuáles puedan ser esas otras indemnizaciones, no existe motivo para descartar la indemnización por daño moral, apareciendo esta norma como un reconocimiento de la posibilidad de que los perjuicios causados al trabajador no sean adecuadamente resarcidos con las indemnizaciones por años de servicios, su recargo y la sustitutiva del aviso previo.

Por repetido que aparezca, conviene tener presente que el Derecho del Trabajo nace como la respuesta a la insuficiencia de las normas contractuales civiles para conferir regulación a una relación contractual, en que las partes no están en un plano de plena igualdad. Pero ello no significa la exclusión absoluta de la aplicación de las normas del Derecho Civil, en los diversos aspectos del desarrollo del contrato de trabajo, que no han sido previstos expresamente por el Derecho Laboral, ya sea en el Código del Trabajo o en su legislación complementaria. Puede recordarse, entonces, lo dispuesto en el artículo 4 del Código Civil, que establece la aplicación preferente de las normas especiales, pero no excluyentes de las civiles. El punto en estudio se desenvuelve en el campo de la responsabilidad civil, materia que no ha sido regulada de manera general en el Código del Trabajo, el que solo ha establecido determinadas indemnizaciones tarifadas a pagar en ciertas situaciones, también previstas, aunque, además, en diversas normas ha contemplado obligaciones para las partes a las cuales no se les ha aparejado una consecuencia jurídica directa, como ocurre, por ejemplo, en el inciso $8^{\circ}$ del artículo $2^{\circ}$ del Código del Trabajo, en que se atribuye a la obligación de no discriminar el carácter de obligación contractual, aun cuando nada se dice de las consecuencias de su infracción. Se ha escrito "La responsabilidad civil es un instituto de aplicación transversal en nuestro derecho, por lo que no se divisa razón para excluir a las relaciones laborales en caso que producto del desenvolvimiento de las mismas se cause daño a alguno de los sujetos, como ocurre en el caso de acoso moral laboral'”.

9 Gamonal Contreras, Sergio y Prado López, Pamela, El mobbing o acoso moral laboral. Santiago, Chile: LexisNexis, 2006, p. 97. 
El punto también ha sido reconocido por la Corte Suprema que ha dictaminado que "la responsabilidad en el Derecho constituye un principio general, el que referido al Derecho Civil se plantea en el axioma que nadie puede dañar a otro sin reparación, en el evento que no concurra una causal de justificación" ${ }^{10}$. No se advierte razón, entonces, para que tal principio no encuentre aplicación en el desarrollo de un contrato de trabajo.

\subsection{LA SITUACIÓN ACTUAL}

En el marco de las reformas procesales laborales, se instauró un procedimiento especial destinado a proteger al trabajador de las vulneraciones a sus derechos fundamentales o, lo que fue entendido igual, a hacer efectiva su tutela judicial. Es evidente que las normas procesales están al servicio de las normas sustantivas y no es dable sostener que, en un estado de derecho, su ausencia específica pueda llevar a la indefensión de los trabajadores.

El procedimiento de tutela contemplado en el artículo 485 del Código del Trabajo, que podríamos llamar propiamente tal, constituye un procedimiento especial que se aplica solo en aquellos eventos delimitados en la ley y exclusivamente en ellos, sin que sea factible, en principio, acumularse con el conocimiento de otras materias. Básicamente, procederá siempre que se trate de una cuestión suscitada en la relación laboral, por aplicación de las normas laborales y que haya afectado el catálogo de derechos fundamentales de los trabajadores enunciados expresamente en el artículo 485. Ello parece un gran avance, pero debe analizarse el asunto en su real dimensión. En efecto, por un lado su conocimiento no ha sido entregado a una instancia constitucional superior, sino a los tribunales ordinarios de justicia, aun cuando se trata de tribunales especiales y especializados en materia laboral. Por el otro, el procedimiento a seguir es el de aplicación general, lo que quiere decir que los sucesivos trámites procesales son los mismos que en cualquier otro problema laboral. Esta afirmación está lejos de significar que no se ha reconocido la importancia que las vulneraciones de esta naturaleza conllevan, especialmente por las particularidades introducidas al procedimiento, transformándolo, a pesar de lo dicho, en un sistema realmente especial y en el que la aplicación del procedimiento general solo se traduce en la sucesión de algunos trámites procesales esenciales que, obviamente, no podrían faltar en ningún procedimiento judicial. El camino elegido no parece reprochable, aun cuando solo se trata de un procedimiento destinado a conocer judicialmente de ciertos asuntos, generados en la violación de determinados derechos fundamentales del trabajador, introduciéndose algunas instituciones que han permitido que pueda llegar a cumplir de manera aceptable su función. Destacan, entre estos aspectos, la obligación del juez de hacer cesar de inmediato las conductas infractoras, bajo apercibimiento de multas; la preferencia para su vista y fallo tanto ante los tribunales especiales como superiores; el reconocimiento de la denominada prueba indiciaria y el contenido ampliado de la sentencia.

\subsection{EL DESPIDO INDIRECTO O AUTODESPIDO Y EL PROCEDIMIENTO DE TUTELA DE DERE- CHOS FUNDAMENTALES \\ Conjugar la situación del autodespido con la tutela de los derechos fundamentales, aun cuando sea por incumplimientos patronales, encierra una contradicción esencial: la tu-}

10 Corte Suprema, autos Rol No 3070-2006. 
tela de los derechos fundamentales que confiere el Código del Trabajo busca, precisamente, su amparo en el desarrollo de la relación laboral. Debe recordarse que el autodespido, en cambio, implica la decisión del trabajador, por muy justificada que sea, de poner término al contrato de trabajo ¿cómo puede pedirse tal amparo si no se desea mantener la relación laboral? Sin embargo, el procedimiento de tutela no se limitó a la hipótesis indicada, la que se puede denominar tutela propiamente tal. Por el contrario, se incluyeron otras posibilidades que no constituyen, en estricto rigor, la tutela en el desarrollo de una relación laboral respetuosa de los derechos fundamentales del trabajador, sino que suponen que ha mediado el despido, reconociendo el derecho a obtener indemnizaciones por los daños causados por la referida vulneración, además, de las respectivas indemnizaciones por término del contrato, lo que hace que estas herramientas se constituyan en un medio indirecto para lograr que el empleador respete los derechos fundamentales o, lo que es lo mismo, como un desincentivo importante en su vulneración.

\subsection{EL PROCEDIMIENTO DE TUTELA EN RELACIÓN CON EL FIN PERSEGUIDO}

Nuestra ley procesal consagró un sistema judicial de protección a los derechos fundamentales, que no pudo desligarse del contenido contractual de la relación laboral y del respeto al derecho del empleador de organizar la empresa, combinación que desembocó en una especie de cumplimiento por equivalencia de la obligación de respeto a los referidos derechos, al mantener la validez de actos vulneratorios, acompañada esa validez del pago de determinadas indemnizaciones. Si bien la idea emana del sistema español, en este punto se apartó radicalmente, aun cuando se mantuvo la norma que impide la acumulación con acciones de otra naturaleza o con idéntica pretensión basada en fundamentos diversos a la tutela (ya contemplada en el artículo 176 de la Ley de Procedimiento Laboral española), lo que ha llevado a afirmar la existencia de una "expulsión" de determinadas cuestiones litigiosas del ámbito del proceso de tutela, tales como el despido y las demás causas de extinción del contrato de trabajo, la vacaciones, materias electorales, impugnación de estatutos de los sindicatos o de su modificación y la impugnación de los convenios colectivos, los que quedan entregados a la modalidad procesal correspondiente ${ }^{11}$.

Dentro de la regulación del procedimiento de tutela de derechos fundamentales, se han distinguido diversas situaciones, que dicen relación con el fin perseguido en cada caso. Así, puede distinguirse el que podría designarse como procedimiento de carácter general, denominado recién propiamente tal, que responde a la idea esencial de la tutela en análisis y cuya finalidad es, precisamente, conferir amparo en el desarrollo mismo de la relación laboral. A través de su ejercicio, se confiere al trabajador la posibilidad de invocar la tutela del juez, a fin de permitirle mantener aquella, pero dentro de los debidos márgenes constitucionales. Este procedimiento encuentra su base en el artículo 485 del Código del Trabajo y me atrevo a sostener que es aquí en donde se destaca el cambio de concepción en la materia de protección laboral, alejándose de la idea de que la única solución al abuso es el término del contrato. Este procedimiento nada tiene que ver con el autodespido, como ya han tenido

11 Palomeque López, Manuel Carlos, "La Tutela Judicial de los Derechos Laborales Fundamentales”. En: Derecho del Trabajo y Razón Crítica. Salamanca, España: Gráficas Varona S.A., 2004, p. 343. 
ocasión de dejarlo en claro nuestros tribunales de justicia. En un caso reciente ${ }^{12}$, frente a una demanda deducida por una trabajadora que invocaba la tutela laboral contemplada en el artículo $485 \mathrm{y}$, al mismo tiempo, el despido indirecto, la demandada interpuso excepciones fundamentadas en la incompetencia del tribunal, precisamente, sosteniendo que la actora había intentado una acción de despido indirecto conjuntamente con la de tutela contemplada en el artículo 489, por lo que no era factible que ambas hipótesis pudieran ventilarse de manera conjunta, ya que si el trabajador se autodespidió, no podría invocar la protección de sus derechos fundamentales por parte del empleador. La jueza del Juzgado de Letras del Trabajo de Concepción rechazó las excepciones considerando que, según se desprendía del tenor de la demanda, se fundamentaba en la lesión de derechos fundamentales ocurrida durante la vigencia de la relación laboral, en cuanto se invocaba el artículo 485 y no con ocasión del despido fundado en el artículo 489.

Acto seguido, haciendo uso de sus facultades oficiosas, contempladas en el artículo 429, que ordena que el juez debe velar por la corrección del procedimiento, resolvió no admitir a tramitación la demanda, en la parte que pretendía que se declarara que el empleador incurrió en un incumplimiento grave de las obligaciones del contrato de trabajo y sus correspondientes indemnizaciones. Se consideró en el fallo, además, la norma contenida en el artículo 487, en cuya virtud este procedimiento de tutela queda limitado, solamente, a tales materias, no correspondiendo, en consecuencia, su acumulación con acciones de otra naturaleza, cual sería la deducción en forma conjunta del despido indirecto. La resolución fue apelada por la actora y confirmada por la Corte de Apelaciones de Concepción, considerando que la demandante planteó, en lo principal de su libelo, claramente una demanda o denuncia de tutela de sus derechos fundamentales, los que habrían sido vulnerados por su empleadora durante la relación laboral. La Corte consideró que esta situación se encontraba contemplada en el artículo 485, incisos $1^{\circ}$ y $2^{\circ}$, del Código del Trabajo y, por consiguiente, y conforme a la prohibición establecida en el artículo 487 del mismo Código, el procedimiento de tutela laboral de derechos fundamentales no se podía acumular con "acciones de otra naturaleza o con idéntica pretensión basada en fundamentos diversos". Importante resulta destacar que el tribunal de alzada agregó, además, que:

"no procede aplicar a este caso el procedimiento especialísimo establecido en el artículo 489 del Código del Trabajo, pues este tiene lugar cuando se han vulnerado derechos fundamentales del trabajador con ocasión de su despido, cuyo no es el caso, pues el empleador no ha realizado despido alguno, y lo que se ha reclamado ha sido la violación de tales derechos durante la vigencia de la relación contractual. Pero, aunque hipotéticamente así pudiese estimarse, la demanda por despido indirecto debió interponerse en subsidio de la denuncia por infracción de derechos fundamentales, de acuerdo a lo que ordena el inciso final del artículo 489 del Código laboral, lo que no se hizo"13.

\footnotetext{
12 Juzgado de Letras del Trabajo de Concepción, causa Rol T-53-2010.

13 Corte de Apelaciones de Concepción, fallo de 1 de abril de 2011, causal autos Rol No 9-2011.
} 
Estos puntos enunciados en la sentencia serán analizados más adelante.

El fallo amerita algunos comentarios. Por lo pronto y, en principio, estimo que no es factible deducir conjuntamente la acción del artículo 485 con la del despido indirecto, ya que ello encierra una contradicción vital, pues mientras la esencia de la primera es la conservación del trabajo respetuoso de los derechos fundamentales del trabajador, la segunda supone su decisión de ponerle término al contrato. Sin embargo, el texto de la ley no es tan claro, ya que nada hay en la norma del artículo 485 que exija que la acción se intente mientras esté vigente la relación laboral ${ }^{14}$. En efecto, la exigencia es que la cuestión que lo motiva se haya suscitado en la relación laboral. Complica un tanto esta conclusión la norma contenida en el inciso $2^{\circ}$ del artículo 495, que obliga al juez, en cualquier caso, esto es, sea cual sea las resoluciones que adopte, a velar para que la situación se retrotraiga al estado inmediatamente anterior a producirse la vulneración denunciada, absteniéndose de autorizar cualquier tipo de acuerdo que mantenga indemne la conducta lesiva de derechos fundamentales. Por un lado, ello parece difícil de lograr si el trabajador afectado ya no se encuentra en la empresa, pero, por el otro, no puede olvidarse que el fin perseguido por este procedimiento tiene una connotación colectiva y lo dictaminado dirá relación con la vida normal en la empresa y no solamente con lo acontecido con un trabajador en particular. Además, el numeral 3 del artículo 495 da la posibilidad de disponer la indemnización de perjuicios al afectado y es insostenible concluir que la pierda, solamente por haber terminado la relación laboral. Se advierte aquí, el contenido contractual que el tema presenta, el cual no se extingue por haber terminado el contrato. En síntesis, entonces, es de la esencia de la acción del artículo 485, que se invoque la tutela judicial para el desarrollo respetuoso de los derechos fundamentales, lo que, curiosamente, siguiendo el tenor de la ley, no obsta a que, si ha concluido la relación laboral, el trabajador pueda demandar los perjuicios causados por los atentados a sus derechos fundamentales. Pero mal podría intentarse esta acción conjuntamente con las emanadas del despido indirecto, por impedirlo el artículo 487.

\subsection{LAS ACCIONES CONTEMPLADAS EN EL ARTíCUlO 489 DEL CÓdigo DEL TRABAjO}

En lo que atañe al tema en estudio, la tutela laboral fue tratada por nuestro legislador diferenciando dos hipótesis básicas concretas: si se busca el amparo en el desarrollo de la relación laboral o la reparación de los efectos de un despido abusivo de los mismos.

En el primer caso y si bien, como se adelantó, la regla general del artículo 485, no hace limitaciones ni exige que se demande mientras está vigente la relación laboral, la idea de tutela de sus derechos hace pensar, necesariamente, que lo que busca el trabajador es que el juez lo proteja, lo ampare en su trabajo en condiciones respetuosas a sus derechos fundamentales, lo que se relaciona directamente con las resoluciones que los artículos 490, 491 y 495 del Código del Trabajo, hacen procedentes, al ordenar al juez aplicar las medidas para evitar que la conducta vulneratoria se mantenga. Se trata, precisamente, de lograr un amparo efectivo a la mantención del trabajo digno, decente, respetuoso de los derechos inherentes al ser humano.

\footnotetext{
14 Ello resulta consecuente con la aplicación del procedimiento frente a represalias del empleado, las que perfectamente pueden consistir en su despido. Negar la aplicación del procedimiento de tutela, en este caso, es inconcebible.
} 
Insertar la institución del autodespido en esta tutela resulta complejo. Podría defenderse la idea de que la ley no distingue y que en las "indemnizaciones que procedan" a que se refiere el artículo 495, deben comprenderse no solo las de los artículos 162 y 163, sino también aquellas que satisfagan de alguna manera el daño a los derechos fundamentales, la que no está tasada como en el artículo $489^{15}$. Pero ello se contrapone, en esencia, a lo buscado en este especial procedimiento. En conclusión y como ya se analizó, esta hipótesis es incompatible con la del despido indirecto.

Para la segunda hipótesis, se contempló la situación del artículo 489 y, aunque pese decirlo, no es más que el reconocimiento legislativo al carácter esencialmente contractual que impregna la relación laboral y que, en nuestra realidad, se traduce en la preferencia del trabajador a la pérdida de la fuente laboral, si va acompañada de una buena indemnización, antes que invocar la tutela en su desarrollo respetuosa de los derechos fundamentales. Tan es así, que la mayor parte de las causas ventiladas ante los tribunales obedecen a esta fórmula. Por lo demás, demuestra lo señalado la sola consagración de la institución del despido abusivo, sancionada con el pago de una indemnización y solo por excepción, con la reincorporación del trabajador, a petición de este, en el caso de haber mediado discriminación grave. El despido abusivo, en otros sistemas como el español, argentino o peruano, simplemente, es un despido nulo. Los problemas de interpretación de la legislación positiva obedecen, precisamente, a esa verdadera dicotomía.

Antes de las modificaciones de la Ley $\mathrm{N}^{\circ} 20.260$, se disponía que el plazo para reclamar por despido injustificado, indebido o improcedente, se suspendía mientras se tramitaba la acción de tutela. Las modificaciones introducidas por esa ley, tuvieron por objeto permitir al trabajador demandar en el mismo juicio, aun cuando de manera subsidiaria, evitando demoras innecesarias, pero también un cúmulo de indemnizaciones injustificadas. Sin embargo, y aunque no parece haber sido esa la intención, el tenor literal de la norma actual, para efectos de su análisis, permite diferenciar las siguientes situaciones:

a) Situación del artículo 489 inciso $1^{\circ}$, que utiliza expresiones que parecen limitar su aplicación, esto es, que la vulneración debe haber sido con ocasión del despido, y si bien no se exige que sean simultáneas, deben estar relacionadas directamente con este. La primera lectura lleva, necesariamente, a concluir que debe haber sido el despido mismo el que motivó la vulneración, como si fue discriminatorio, se insultó al trabajador al despedirlo, o en la misma carta aviso se le atribuyen conductas vejatorias, se atentó en contra de su dignidad o en contra de su privacidad. Sin embargo, ocasión, según el Diccionario de la Real Academia Española, significa causa o motivo por el que se hace o acaece algo, por lo que, válidamente, se puede concluir que los hechos vulneratorios no se producen de manera simultánea con el despido, sino que son su causa.

b) Situación del inciso $7^{\circ}$ del artículo 489 , primera parte, que se refiere a aquellos casos en que, de los mismo hechos emanen dos o más acciones de naturaleza laboral, y una de

15 Incluso, durante el estudio de la Ley $\mathrm{N}^{\circ} 20.260$ en el Congreso, se propuso reemplazar en la norma del № 3 del artículo 495, la frase "incluidas las indemnizaciones que proceden" por "incluidas las indemnizaciones que procedan de conformidad a lo establecido en el inciso tercero del artículo 489 del presente Código", indicación que fue rechazada. Ver Congreso Nacional, Historia de la Ley $N^{\circ} 20.260$, p.189. 
ellas sea la de tutela laboral de que trata el párrafo $6^{\circ}$ y la otra no es la acción de despido injustificado, indebido o improcedente.

La regla no es clara. En primer lugar, alude a la acción de tutela a que hace referencia “este párrafo", pero ¿cuál acción de tutela?: ¿la del artículo 485 o del inciso $1^{\circ}$ del artículo 489? En el párrafo se incluyen ambas y no solamente a la acción regulada en el artículo 489, o sea, en principio y según el tenor literal de la norma, se contemplaría la posibilidad de accionar conjuntamente con las hipótesis de los artículos 485 y 489, introduciéndose una excepción al artículo 487. Sin embargo, siempre debe haber mediado un despido, pues de lo contrario no estaríamos en la hipótesis del artículo 489, aun cuando, en teoría, parece posible unirla con la acción contemplada en el artículo 485, en la medida que se cumplieran todos y cada uno de los requisitos que tal norma contempla y, desde luego, el trabajador no buscará la tutela en el ejercicio de su relación laboral, sino la indemnización de los perjuicios que se le causaron con la conducta del empleador y, casi de paso, que se haga efectivo el real rol de este procedimiento, cual es su tutela colectiva en el lugar de trabajo. En realidad, parece ser, más bien, una impropiedad de la norma y no una razón suficiente para considerar que se ha establecido una excepción al artículo 487.

Las dudas siguen. Debe determinarse a qué se refiere la norma cuando señala de los mismos hechos: ¿son los que ocasionan la lesión a los derechos fundamentales?, ¿puede el hecho ser el despido?, ¿se refiere a la misma situación planteada en el inciso primero? Como el supuesto básico de esta acción es precisamente la vulneración de los derechos fundamentales, estimo que el hecho del cual emanan las acciones debe ser precisamente el que causa la lesión. No se trata, entonces, de acciones que puedan, simplemente, sumarse, como sería el despido más la infracción a derechos fundamentales. Subsiste la duda en relación a si esta situación es la misma del inciso primero o se refiere a otra hipótesis diferente. Sostener lo primero, lleva a concluir que, cuando la norma se refiere a que la vulneración debe producirse con ocasión del despido, los hechos deben ser simultáneos, es decir, los mismos, lo que no parece ser así, sino que pueden ser otros en la medida que sean su causa.

En esta hipótesis, la ley exige que los hechos de los cuales emanan las acciones sean "los mismos". Obviamente, el despido en sí no es el hecho que ocasiona la lesión a los derechos fundamentales, salvo que vaya acompañado de alguna otra conducta. El hecho que origina ambas acciones es, precisamente, el despido abusivo, circunstancias complejas que forman un todo y que no siempre es factible separar. Ahora bien, de ello debe emanar una acción, además de la de tutela y que, consecuentemente, tenga algún contenido, es decir, persiga alguna compensación, aun cuando pueda no ser de naturaleza económica, pero diferente a las ya contempladas en la ley para la tutela, aspecto que lleva a determinar la naturaleza jurídica de las indemnizaciones que contempla el inciso $3^{\circ}$ del artículo 489.

a) Los primeros resarcimientos a que hace referencia la ley son la indemnización sustitutiva del aviso previo y por años de servicios. La norma busca evitar que el trabajador que ha sido víctima de un despido abusivo se vea privado de ellas, que persiguen un fin diferente. 
b) Indemnización adicional. La doctrina nacional no está conteste en la naturaleza jurídica de esta última. Gamonal postula que:

"esta indemnización no es una simple tarificación por antigüedad, sino que deja un margen de apreciación importante al juez de la causa, acerca del daño producido, especialmente el moral. De esta forma, el legislador fija un piso y un tope dentro del cual evaluar los daños, recogiendo la experiencia de otros países en los que se ha evaluado el daño moral laboral por medio de la tarifa legal por años de servicios" 16 .

Ugarte, en cambio, considera que la referencia que el artículo 495, numeral 3, hace a la inclusión de las indemnizaciones que procedan, se refiere a la reparación del daño moral, "ya que la única indemnización que podría proceder, adicional a las que ya están reguladas expresamente en la ley, corresponde a las de este tipo" ${ }^{17}$. Sin embargo, el autor hace referencia al pago de otros rubros que, en realidad, vienen a ser indemnizaciones por el daño material causado a los trabajadores producto del despido abusivo, como ocurriría en el caso de que en razón de la conducta lesiva, el trabajador haya dejado de recibir un beneficio salarial, es decir, reconoce la posibilidad de que se engloben en esas otras reparaciones, también aquellas destinadas a resarcir el daño material ocasionado al trabajador ${ }^{18}$. Sintetiza el tema explicando que la ley determina una indemnización propiamente laboral, tasada, que cubre el daño económico por el despido, el recargo indemnizatorio por la causal, en conformidad al artículo 168 y una indemnización que califica de sancionatoria fijada discrecionalmente por el juez.

Debe recordarse que el Derecho del Trabajo no contiene una teoría general de responsabilidad civil, debiendo estarnos a las normas que el Código Civil dispone, en lo no modificado por su homólogo laboral. No resultan extrañas a las normas civiles la posibilidad de que la evaluación de los perjuicios la ley la entregue al juez, no existiendo inconveniente que, como ocurre en la especie, se produzca una combinación de ambas fórmulas, pero ello nada tiene que ver con la naturaleza misma de la indemnización que se impone. Pero no parece ser una sanción impuesta al empleador. Concuerdo en que, como dijo Tapia ${ }^{19}$, la responsabilidad civil implica siempre la violación de una obligación preestablecida; busca, entonces, sancionar un incumplimiento, pero ese incumplimiento se sanciona a través de la indemnización de los daños y perjuicios que se impone al infractor ${ }^{20}$. Por lo demás, la

\footnotetext{
16 Gamonal Contreras, Sergio, El Procedimiento de Tutela de Derechos Laborales. Tercera edición revisada y actualizada. Santiago, Chile: LegalPublishing, 2008, p. 39.

17 Ugarte Cataldo, José Luis, Tutela de Derechos Fundamentales del Trabajador. Tercera edición. Santiago, Chile: LegalPublishing, 2010, p. 90 .

18 Ibid., p. 89.

19 TAPIA SUÁREZ, Orlando, De la Responsabilidad Civil General y de la Responsabilidad Delictual entre los Contratantes. Segunda edición. Santiago, Chile: LexisNexis, 2006, p. 443.

20 En este mismo sentido, Pablo RodríGUEZ GREZ, para quien, cuando dos sujetos están ligados por un contrato existe una conducta "programada"; si no se realiza, su consecuencia es que deberá compensar a la persona afectada en sus bienes o intereses, es decir, se genera una conducta de reemplazo destinada a substituir el incumplimiento contractual, que tiende a restaurar el orden "programado" por la ley o el contrato de manera que logren, por medio equivalente, los mismos objetivos expresados en el respectivo instrumento. "De allí que hayamos definido la sanción como el efecto que se sigue del incumplimiento y que consiste
} 
propia ley hizo referencia a ello calificándola de indemnización ${ }^{21}$. Dada la especial naturaleza de la infracción contractual cometida por el empleador, lo que se está indemnizando parece ser el daño moral ocasionado por la lesión a sus derechos fundamentales. Cuando el artículo $495 \mathrm{~N}^{\circ} 3$ agrega a la indicación de las medidas concretas que debe adoptar el juez, la mención de las "las indemnizaciones que procedan", lo hace de una manera genérica y bien puede referirse a las ya indicadas en el artículo 489, reiterando que debe pronunciarse al respecto, pero también puede entenderse que se deja abierta la posibilidad de disponer la indemnización de todo daño que pueda haberse ocasionado al trabajador y que, estime, no ha quedado debidamente resarcido con las indemnizaciones tarifadas establecidas en la ley. Ello explica que, durante el estudio de la respectiva ley en el Congreso, no se haya aprobado la indicación de modificación en el sentido de agregar, de manera expresa, la referencia al inciso $3^{\circ}$ del artículo $489^{22}$.

Por lo demás, esta posibilidad fue reconocida por la Corte Suprema, aun cuando en otro escenario procesal, en una situación en que determinó que existía responsabilidad extracontractual por los daños causados con un despido, los que consistían en la dificultad de encontrar un nuevo trabajo, atendida la edad del trabajador despedido al considerar que:

"Se trata de una atribución de responsabilidad civil que va más allá del hecho de haber puesto término al contrato de trabajo, toda vez que aquel a quien la demandada desvinculó de su fuente laboral se presenta alegando perjuicios que responden a dos rubros indemnizatorios: el lucro cesante y el daño moral, resultando que de entre ambos, este último admite extender sus contornos hacia aspectos que, según sea el caso y aun de mediar las indemnizaciones previstas por el legislador especial, será palmario que no habrán de resultar debidamente compensados con estas, tal como podría acontecer para un trabajador con escasa antigüedad y exiguo estipendio circunstancias que servirán de proporción a las eventuales indemnizaciones laborales, al que se despide invocando un hecho tan oprobioso, como sabidamente falso y, que así se compruebe. Una hipótesis como la anterior, muestra meridiano que el resarcimiento aparejado a ella se distancia del incumplimiento de las obligaciones contractuales de los integrantes de la relación de trabajo y, es natural, entonces, que de ella se deriven consecuencias que exceden de las puramente laborales.

Confrontado esto último con las prescripciones de la legislación especial del trabajo, puede decirse que, si bien las indemnizaciones derivadas de un despido injustificado por parte del empleador están, en principio, limitadas por la reglamentación que el Código del

en la realización por medios coercitivos, de una conducta de reemplazo que tiene por objeto restaurar el orden social quebrantado". La responsabilidad es, en sentido amplio, una sanción, puesto que sustituye por medio de la fuerza la conducta que se quebrantó y que debía desplegarse por mandato legal o contractual. Por lo mismo, es un medio alternativo para la consecución de los objetivos que se procuraba legítimamente obtener, esto es, la satisfacción de los intereses que era lícito alcanzar. Concluye que están representados por la prestación y que el acreedor, por lo mismo, no puede aspirar a recuperar por esta vía otros beneficios que no sean estos. Véase su Responsabilidad Contractual. Santiago, Chile: Editorial Jurídica de Chile, 2003, pp. 328-329.

21 En este sentido Prado López, Pamela, "Breves Notas Sobre la Responsabilidad Civil del Empleador en el Nuevo Procedimiento de Tutela Laboral”. En: CORRAL TALCIANI, Hernán et al. (coordinadores), Estudios de Derecho Civil. Tomo II. Santiago, Chile: Editorial Abeledo-Perrot, 2011, pp. 261-272.

22 Indicación del Senador Allamand. Congreso Nacional, op. cit. (n. 15), p. 189. 
Trabajo fija al respecto, ellas no excluyen que, en caso especiales y si se prueban perjuicios extraordinarios, como lo sería el daño moral experimentado por el trabajador abusivamente despedido, pueda reconocerse en favor de este último una indemnización adicional, no prevista especialmente por la ley laboral, la cual solo contempla rubros tarifados, regulando legalmente el monto de los perjuicios"23.

Sin embargo, no puede entenderse que solo se refiere al daño moral, pues el daño patrimonial por la vulneración no está graduado en norma alguna. En efecto, la indemnización proporcionada a la antigüedad solo pretende dejar indemne los derechos que la ley laboral ya le otorgaba al trabajador en el sistema de amparo al despido indebido, injustificado o improcedente, adicionando ahora a ella la indemnización por la lesión a los derechos fundamentales. Pero bien podría ser, como lo indica Ugarte, que producto de esta situación el trabajador haya sufrido algún daño patrimonial, como ocurriría, por ejemplo, si producto de la discriminación de que fue objeto no recibió alguna remuneración o beneficio especial, en cuyo caso tendrá derecho para accionar pidiendo su pago, aun cuando pueda entenderse que se trata de una especie de cumplimiento por equivalencia, pero, en nuestro sistema, qué duda cabe, se trata de una indemnización por daño patrimonial, cuyo reconocimiento legislativo descansa en el No 3 del artículo $495^{24}$. Pamela Prado señala, refiriéndose al daño patrimonial, que, como consecuencia directa de la vulneración del derecho fundamental, puede producirse un daño que puede ser emergente o lucro cesante, conforme a lo establecido en el artículo 1556 del Código Civil, considerando, a vía de ejemplo, entre los primeros los gastos médicos por atención psiquiátrica de la víctima, no cubiertos por su sistema de salud y, entre los segundos, los montos de remuneración no cubiertos por la licencia médica. Pensemos, siguiendo con la vía ejemplar, que se refiere a alguna conducta del empleador atentatoria a los derechos fundamentales del trabajador, pero que puede implicar que este persiga no solamente el cese de la misma, sino otras prestaciones que puedan proceder, tal como podría ocurrir en aquellos eventos en que se vulnerara el derecho a la integridad física o psíquica del trabajador y que proceda a ejercer conjuntamente con la acción de tutela, las que le concede el artículo 69 de la Ley No 16.744 que, obviamente, son acciones de naturaleza laboral, que no dicen relación con el reclamo del despido injustificado, indebido o improcedente, punto que da lugar a un interesante problema, atendido que, seguramente pretenderá perseguir también la indemnización del daño moral ocasionado por el accidente, aspecto cuyo análisis detallado escapa a este estudio.

23 Causa Rol No 7.270-09, de 4 de abril de 2011. Las cursivas son mías.

24 Resulta interesante recordar lo ocurrido en la causa Rol No 124-2009, de la Corte de Apelaciones de Concepción, tramitada en el procedimiento anterior, en que se condenó a la empresa empleadora al pago de una indemnización del daño patrimonial, causado a los trabajadores por haber sido víctimas de discriminación laboral. La indemnización dispuesta fue del monto del bono que el empleador se había negado a pagar, por tratarse de trabajadores sindicalizados. La Corte Suprema, anteriormente, conociendo de la práctica antisindical (causa Rol № 1.203-09), sancionó a la empresa, multándola por haber incurrido en la infracción tipificada en el artículo 289 , letra f), esto es, por haber ejercido discriminaciones indebidas entre trabajadores con el fin exclusivo de incentivar o desestimular la afiliación sindical. Después de ello, los trabajadores demandaron derechamente el pago del bono, aun cuando sin hacer calificaciones jurídicas que justificaran su procedencia. En definitiva, la Corte de Apelaciones de Concepción consideró que se trataba de una indemnización por la infracción contractual, tipificada en el artículo $2^{\circ}$ del Código del Trabajo, y condenó a la empresa al pago del bono a título de indemnización del daño patrimonial causado. En el actual procedimiento, esta indemnización se encasillaría en la norma del $\mathrm{N}^{\circ} 3$ del artículo 495 . 
Se trata, en la especie, del término del contrato decidido por una de las partes, el empleador, despido que es declarado no solo contrario a la ley, sino abusivo y, consecuencialmente, se ordena su indemnización. Es decir, se trata de un afán indemnizatorio establecido en contra de un contratante incumplidor. El punto debe relacionarse con la función que desempeña la responsabilidad civil, tema que ha dado lugar a más de alguna discusión.

Los hechos de los cuales emanan las acciones deben ser "los mismos". Obviamente debe tratarse de la vulneración de los derechos fundamentales enumerados en el artículo 485, pero la pregunta es: ¿y el despido? La referida vulneración no emana del despido. ¿Y el despido abusivo, como un todo complejo? Evidentemente que ello sí puede ser. La pregunta es, entonces: ¿pueden unirse las acciones que emanan del despido abusivo con las de un simple despido, como sería la indemnización del feriado proporcional o de la nulidad del despido? Aun cuando parece discutible que esas acciones puedan emanar de los mismos hechos, ni nuestros tribunales ni las partes han hecho mayor cuestión, tal vez por razones de economía procesal, evitando así que el trabajador deba demandar en forma separada para obtener dichas indemnizaciones. Aun cuando puede ello entenderse desde el punto de vista práctico, constituye un claro menosprecio a lo que es, en sí, el procedimiento de tutela, menosprecio que viene a adicionarse al que efectuó el propio legislador, al establecerlo como un asunto que se ha traducido, en la práctica, en una forma de encarecer el despido ${ }^{25}$. Sin embargo, parece ser que se trata de acciones que no emanan de los mismos hechos. La mal llamada nulidad del despido, proviene del despido sin pago de cotizaciones, pero no del despido abusivo de derechos fundamentales enumerados en el artículo 485, por lo que mal puede entenderse que se tratan de acciones que derivan de los mismos hechos. El feriado proporcional procede en el caso de terminación del contrato de trabajo, estando pendiente la utilización de la proporción de feriado. Nada tiene que ver con el despido abusivo, aun cuando sí con el despido, por lo que su inclusión podría ser considerada. Entonces ¿qué acciones pueden emanar de los mismos hechos, esto es, de una lesión a los derechos fundamentales? La norma tiene por objeto permitir que las acciones para el cobro de las indemnizaciones a que se refiere el artículo 489, inciso $3^{\circ}$, puedan demandarse conjuntamente, aclarando que no se infringe lo dispuesto en el artículo 487, pero, sin duda, abre la posibilidad de que puedan demandarse aquellas indemnizaciones que no se contemplan en la norma, tal como el daño patrimonial experimentado por la vulneración de los derechos fundamentales y, posiblemente, el feriado proporcional.

c) Situación del inciso $7^{\circ}$ del artículo 489, segunda parte, que se refiere a aquellos casos en que, de los mismos hechos, emanen dos o más acciones de naturaleza laboral y una de ellas sea la acción de despido injustificado, indebido o improcedente.

Esta fue la acción que motivó la modificación de la norma y, tal vez, que motiva cada una de sus prescripciones. Se trataba de evitar la duplicidad de juicios, por un lado, y de indemnizaciones, por el otro. Se exige que las acciones se interpongan de manera subsidiaria y deja de tener aplicación la preferencia que contempla el artículo 488. Si no se ejercen las acciones en esta forma, se entiende que ha renunciado a ellas.

25 No se contempló la nulidad del despido abusivo, salvo en el caso del despido discriminatorio y a opción del trabajador, posibilidad que no es habitual que se invoque. 


\subsection{EL DESPIDO INDIRECTO Y LAS ACCIONES CONTEMPLADAS EN EL ARTÍCULO 489 DEL CÓDIGO DEL TRABAJO}

Ya se ha dilucidado que no es posible deducir conjuntamente la acción de despido indirecto con la acción que concede el artículo 485, ni tampoco esta última con otras acciones, por impedirlo el artículo 487. Asimismo, tampoco cabe la acumulación de acciones en los casos del artículo 489, salvo las situaciones excepcionales que la misma norma indica.

La pregunta que resta formularse ahora es la posibilidad de deducir, en un mismo juicio, la acción de despido indirecto y alguna de las acciones que contiene el artículo 489, ya sea de manera conjunta, si se considerara que emanan de los mismos hechos, o de manera subsidiaria, en conformidad al inciso séptimo, en su última parte, de la misma norma. Previo al análisis, debe considerarse que se trata de la decisión del trabajador de poner término al contrato, debido a los incumplimientos del empleador. Es un tema de la esencia del carácter contractual que une a las partes, en que uno de los contratantes opta por la terminación de un contrato frente a la posibilidad de continuar ligado al contratante incumplidor. La idea se encuadra en el reconocimiento de la condición resolutoria que va envuelta en todo contrato bilateral, de no cumplirse por uno de los contratantes lo pactado, recogiendo la idea consagrada en el artículo 1489 del Código Civil, advirtiendo, eso sí, que la situación está contemplada de manera expresa en el artículo 171 del Código del Trabajo, que marca un camino a seguir por el trabajador frente a determinados incumplimientos por parte del empleador y las indemnizaciones a obtener, en el caso de determinarse que, efectivamente, incurrió en el incumplimiento. No puede dejar de mencionarse que se contempla entre las causales que habilitan para decidir la terminación del contrato la genérica contenida en el artículo $160 \mathrm{~N}^{\circ} 7$ del Código del Trabajo, esto es, el incumplimiento grave de las obligaciones que impone el contrato, quedando entregada al juez la calificación tanto de la existencia del incumplimiento como de su gravedad. De determinarse lo contrario, se entenderá que el trabajador renunció al trabajo.

En la reforma procesal laboral, simplemente, no se pensó ni consideró para nada el autodespido. Es más, la única alusión al mismo durante el estudio de la Ley № 20.087 en el Congreso, fue una moción rechazada por unanimidad que proponía intercalar un inciso al actual artículo 168, en el sentido que las indemnizaciones por años de servicio, no excluían el derecho del trabajador para exigir la reparación de los perjuicios extraordinarios que, en materia extrapatrimonial, se le hubieran causado con ocasión de un despido abusivo, uno declarado injustificado, indebido, improcedente o sin invocación de causal, o por uno en que se hubiera procedido según lo dispuesto en el artículo 171, atendiendo sus circunstancias, motivaciones y consecuencias ${ }^{26}$. La norma no fue aprobada, regulándose derechamente la institución del despido abusivo de derechos fundamentales en el artículo 489, bajo la fórmula de la llamada vulneración de derechos fundamentales con ocasión del despido.

Si bien, como se dijo, el despido indirecto no fue considerado dentro del nuevo esquema procesal, parece pertinente, sin embargo, analizar la posibilidad de que tenga cabida en las normas positivas que regulan, particularmente, la vulneración de derechos fundamentales con ocasión del despido.

26 Congreso Nacional, op. cit. (n. 15), p. 260. 


\section{a) Posibilidad de deducir ambas acciones conjuntamente, por estimar que emanan de los mismos hechos.}

Por ejemplo, pensemos en una situación de acoso laboral permanente al trabajador, que culmina con su decisión de automarginarse de la organización empresarial. Perfectamente puede concluirse que de los mismos hechos, esto es, de los acosos reiterados emanan dos acciones, la del despido indirecto y la de tutela. Sin embargo, la ley no parece ponerse en esa hipótesis, por las siguientes razones:

- Su tenor literal. La norma se refirió concretamente al despido del trabajador ${ }^{27}$. Este argumento podría ser válidamente rebatido, si se considera que el autodespido o despido indirecto obedece, en realidad, a la repuesta a una conducta del propio empleador incumplidor, es decir, puede considerarse, desde cierto punto de vista, análogo al despido injustificado, indebido o improcedente. Ambos descansan en una especie de condición resolutoria y bien podría considerarse que el despido indirecto es la especie dentro de un género que es el despido.

- El régimen indemnizatorio que ha contemplado la norma. Un análisis integral de la disposición, lleva a concluir que no se advierte cómo podría entenderse incluido el despido indirecto en esta hipótesis, si el inciso $3^{\circ}$ del artículo 489 ordena que, de acogerse la denuncia, el juez debe disponer el pago de las indemnizaciones de los artículos 162 y 163, más los recargos del artículo 168. Nada dice del artículo 171, que establece de manera concreta y directa un régimen indemnizatorio especial, diferente al de estas disposiciones. En otras palabras, no tiene ninguna lógica pensar que en esta especial acción se hayan modificado las indemnizaciones específicas del artículo 171. La respuesta es que, simplemente, no se consideró en esta hipótesis. Incluso el mismo artículo 171 , en el inciso $2^{\circ}$, le confiere al trabajador la posibilidad de reclamar, de manera conjunta con las indemnizaciones laborales propias de la terminación del contrato de trabajo, simultáneamente, las otras indemnizaciones a que tenga derecho, estableciendo su compatibilidad, con las indemnizaciones por años de servicios, su recargo y la sustitutiva del aviso previo, tratándose de determinadas causales.

Por otra parte, además de la compatibilidad enunciada, la redacción de la norma lleva a concluir que estas otras indemnizaciones pueden existir como alternativa a las derivadas de la terminación del contrato. No obstante que el Código del Trabajo nada dice sobre cuáles puedan ser esas otras indemnizaciones, no existe motivo para descartar la indemnización por daño moral, apareciendo esta norma como un reconocimiento de la posibilidad de que los perjuicios causados al trabajador no sean adecuadamente resarcidos con las indemnizaciones por años de servicios, su recargo y la sustitutiva del aviso previo. Según ya se dijo, el artículo 489 establece pautas para que el juez determine el monto de los perjuicios ocasionados por el daño moral, ¿cómo podría ello conciliarse con la norma del inciso $2^{\circ}$ del artículo

27 En este sentido, Corte de Apelaciones de Concepción, fallo de 1 de abril de 2011, causal Rol No 9-2011. 
171? De aceptar la inclusión de la institución en la figura del artículo 489, no se entendería cómo conciliarlo con las normas propias del autodespido. Una opción sería entender que el artículo 489 se aplicaría cuando se trate de causales diferentes a las del artículo $160 \mathrm{~N}^{\circ} 1$, letras a) y b), conclusión que no parece tener mayor lógica o, deberíamos entender, que la norma del artículo 171 ha quedado derogada tácitamente, cuando se invoca la tutela, dando origen a dos sistemas paralelos de indemnización en el caso del despido indirecto, lo que tampoco tiene sentido alguno.

\section{b) Posibilidad de considerar que se trata de una forma de despido indebido}

Queda preguntarse, aún, si puede considerarse incluida la acción de despido indirecto en la hipótesis del inciso $7^{\circ}$ del artículo 489, parte final, es decir, si puede pensarse que, de los mismos hechos emanan dos o más acciones, una de ellas, la de tutela de derechos fundamentales del párrafo sexto, y la otra, la de autodespido. Desde ya, debe descartarse la del artículo 485 (ya analizado) y, la del inciso $1^{\circ}$ del artículo 489 también parece que debe ser descartada, pues ella va acompañada de las indemnizaciones indicadas en el inciso tercero que no son las del artículo 171. Pero todavía podemos preguntarnos si el despido indirecto puede ser considerado como una forma de despido injustificado, específicamente, indebido y, por tanto, encontrarse en la situación de la segunda parte del inciso $7^{\circ}$ del artículo 489 que, excepcionalmente, establece la forma en que debe intentarse la acción de despido injustificado, norma que hace excepción al impedimento impuesto por el artículo 487 y que busca evitar un cúmulo de indemnizaciones. No parece procedente aplicar la misma norma para el despido indirecto ya que, como dijimos, esta institución no fue incluida en la hipótesis principal del despido abusivo. En efecto, la norma descansa solamente sobre el sistema indemnizatorio del despido propiamente tal, esto es, de aquel que emana de la voluntad del empleador y fue esa precisamente la posibilidad que se quiso precaver al permitirle al trabajador ejercer las acciones en el mismo juicio, aun cuando de manera subsidiaria, superando los problemas que producía la norma anterior.

Confirma la conclusión expuesta la historia fidedigna del establecimiento de la ley. Recordemos que la norma original introducida por la Ley $\mathrm{N}^{\circ} 20.087^{28}$, se hacía cargo de este problema, refiriéndolo siempre, exclusivamente y de manera expresa al derecho del trabajador a reclamar del despido como injustificado, indebido o improcedente a que se refiere el artículo 168, contemplando una especie de suspensión del plazo de caducidad respectivo. Ya en el mensaje con que se dio inicio a la tramitación de la Ley $\mathrm{N}^{\circ} 20.260$, a cuyas modificaciones obedece el actual texto, se señaló que lo que se pretendía con esta modificación era:

“(...) explicitar la posibilidad que tiene el demandante en orden a entablar, en el mismo juicio, la acción de tutela laboral y la acción por despido injustificado, indebido o improcedente, esta última como subsidiaria de aquella.

\footnotetext{
28 La norma del antiguo inciso final del artículo 489 era del siguiente: "Con todo, y sin perjuicio de lo dispuesto precedentemente respecto del plazo para solicitar la calificación del despido como injustificado, indebido o improcedente a que se refiere el artículo 168, se aplicará lo dispuesto en el artículo 448 y solo comenzará a correr luego de quedar ejecutoriada la sentencia que desestime la denuncia por vulneración de derechos fundamentales". El artículo 448, a su vez, contemplaba la suspensión de los plazos de determinadas acciones, mientras se tramitaban otras.
} 
Con esta modificación se apunta a evitar la duplicidad de procesos entre las mismas partes, esto es, primero una acción de tutela y luego un procedimiento de aplicación general, considerando especialmente que aquella se somete a la tramitación de este último, salvo puntuales excepciones, resguardándose de esta manera que el volumen de ingreso de causas a la judicatura se mantenga dentro de parámetros habituales" 29 .

La idea durante toda la tramitación de la ley fue esta: nunca se consideró ni aludió siquiera al despido indirecto, sino que, por el contrario, se tuvo siempre presente que la tutela es un procedimiento especial y que las normas que permiten deducir en el mismo juicio otras acciones son de carácter excepcional. En diversas exposiciones ante la Cámara de Diputados los representantes del Gobierno dejaron en claro que, además de lo dicho, se buscaba evitar decisiones contradictorias ${ }^{30}$. Ante el Senado indicaron que se buscaba resolver el problema que podría generar el ejercicio de la doble acción que puede provocar el despido injustificado, estableciendo que se debería ejercer una acción en subsidio de la otra. Es decir, cuando el trabajador estime que se han vulnerado sus derechos fundamentales y se ha producido el despido injustificado, deberá ejercer ambas acciones en un mismo proceso, y la acción de despido en subsidio de la acción de tutela, de forma tal que no sea posible acoger las dos pretensiones, con lo que se busca evitar que el ejercicio independiente de ambas acciones genere un cúmulo de indemnizaciones respecto de un mismo hecho e, incluso, fallos contradictorios $^{31}$.

\section{CONCLUSIÓN. EL CAMINO A SEGUIR DEL TRABAJADOR QUE NO DESEA PERSEVERAR EN LA RELACIÓN LABORAL, CUANDO HA SIDO VÍCTIMA DE UNA LESIÓN DE DERECHOS FUNDAMENTALES}

Definitivamente, en la actual regulación positiva de las instituciones, la de autodespido o despido indirecto no es una acción que pueda acumularse a la acción de tutela contenida en el artículo 485 del Código del Trabajo ni tampoco a ninguna de aquellas reguladas en el artículo 489 del mismo Código, por mucho que esta conclusión pueda producir una desigualdad de condiciones. Pero no se trata de que el trabajador que se autodespide, por considerar que han sido vulnerados sus derechos fundamentales contenidos en el artículo 485, pierda su derecho a las acciones del artículo 171, sino que no las puede ejercer conjunta ni subsidiariamente en el mismo procedimiento. No debe perderse de vista que se trata de un procedimiento especialísimo no solo por su contenido procesal, sino por su razón material. Nos hemos acostumbrado a traducir la protección laboral en el pago de sumas de dinero, a cualquier título que ello proceda, pero este procedimiento de tutela busca un fin superior, cual es, por repetido que parezca, el amparo del trabajador como ser humano, esa es la razón

\footnotetext{
29 Congreso Nacional, op. cit. (n. 15), p. 8.

30 Informe de la Comisión de Constitución, Legislación y Justicia recaído en el proyecto que modifica el libro V del Código del Trabajo y la Ley No 20.087, que establece un nuevo procedimiento laboral, en: Boletín $N^{\circ} 4.814-13$, p. 39.

31 Segundo Informe de la Comisión de Trabajo y Previsión Social, recaído en el proyecto de ley, en segundo trámite constitucional, que modifica el Libro V del Código del Trabajo y la Ley No 20.087, que establece un nuevo Procedimiento Laboral, en: ibid., p. 9.
} 
que impide que las acciones sean acumuladas. No debe olvidarse que es el propio trabajador el que ejerce su opción, legítima por cierto, de no perseverar en un contrato frente a los incumplimientos de su cocontratante, por graves que hayan sido estos.

Diferente es la situación cuando ha sido el empleador quien procede al despido, figura que, por lo demás, las legislaciones comparadas sancionan con su nulidad, camino no seguido en Chile, salvo por excepción y a elección del trabajador, en el despido discriminatorio de carácter grave. Por ello, la norma del inciso final, excepcionalmente, estableció la carga para el trabajador de accionar de manera subsidiaria, so pena de entender que ha renunciado a la acción no ejercida. Pero esta excepción no puede ser extendida por analogía a otras situaciones diferentes, tanto por tratarse de una excepción, como por la esencia misma del procedimiento de tutela. Como quiera que sea, en este último caso ha sido el propio trabajador que ha optado por el camino de poner término al contrato, por sobre la posibilidad que hoy le confiere la legislación, de invocar la tutela judicial, manteniendo su fuente laboral. Está en su derecho, pero se ve privado de la utilización de las ventajas procesales de la que se ha dotado su defensa, cuando ha sido la voluntad del empleador la que lo ha privado abusivamente de su fuente laboral.

En síntesis, el trabajador no puede ser privado de ninguna de las acciones que la ley le confiere. En efecto, no corresponde hacer efectiva la especie de sanción de renuncia contemplada en el artículo 489 inciso final a otros casos diferentes a aquellos referidos expresamente en la norma y ninguna otra disposición existe que pueda llevar a tal conclusión. Ello lleva a sostener que podrá ejercer la acción que le confiere el artículo 171 y solicitar, también, la indemnización del daño moral que se le pueda haber ocasionado, todo ello en un juicio de aplicación general, esto es, sin las ventajas procesales que le confiere el procedimiento de tutela.

Finalmente, no puede dejar de observarse la incongruencia que encierra la situación descrita. Si se optó por contractualizar la institución, debió incluirse la posibilidad de que fuera el propio trabajador el que pudiera poner término al contrato y accionar en conformidad al artículo 489. No se advierte razón de fondo para que ello no sea así y, por lo demás, donde existe la misma razón, debió existir la misma disposición.

\section{BIBLIOGRAFÍA}

CApArrós, Fernando. “Obligaciones de las partes”. En: ACKerman, Mario E. Tratado de Derecho del Trabajo. Tomo III. Buenos Aires, Argentina: Rubinzal Culzoni Editores, 2005.

CONGReso Nacional. Historia de la Ley $\mathrm{N}^{\circ} 20.087$.

Congreso Nacional. Historia de la Ley $\mathrm{N}^{\circ} 20.260$.

Gamonal Contreras, Sergio y Prado López, Pamela. El mobbing o acoso moral laboral. Santiago, Chile: LexisNexis, 2006.

Gamonal Contreras, Sergio. El Procedimiento de Tutela de Derechos Laborales. Tercera edición revisada y actualizada. Santiago, Chile: LegalPublishing, 2008.

Palomeque López, Manuel Carlos. "La Tutela Judicial de los Derechos Laborales Fundamentales”. En: Derecho del Trabajo y Razón Crítica. Salamanca, España: Gráficas Varona S.A., 2004.

Prado López, Pamela. “Breves Notas Sobre la Responsabilidad Civil del Empleador en el Nuevo Procedimien- 
to de Tutela Laboral”. En: CORRAL TALCIANi, Hernán et al. (coordinadores). Estudios de Derecho Civil. Tomo II. Santiago, Chile: Editorial Abeledo-Perrot, 2011.

Rodríguez Grez, Pablo. Responsabilidad Contractual. Santiago, Chile: Editorial Jurídica de Chile, 2003.

SupIOT, Alian. Crítica del derecho del Trabajo. Informes y Estudios del Ministerio del Trabajo y Asuntos Sociales. Madrid, España, 1996.

TAPIA SuÁREZ, Orlando. De la Responsabilidad Civil General y de la Responsabilidad Delictual entre los Contratantes. Segunda edición. Santiago, Chile: LexisNexis, 2006.

TosCA, Diego y Dragan GIgenA, José Ignacio. “Estabilidad en el empleo”. En: ACKERMAN, Mario E., Extinción de la relación laboral. Buenos Aires, Argentina: Rubinzal Culzoni Editores, 2008.

Ugarte Cataldo, José Luis. Tutela de Derechos Fundamentales del Trabajador. Tercera edición. Santiago, Chile: LegalPublishing, 2010. 


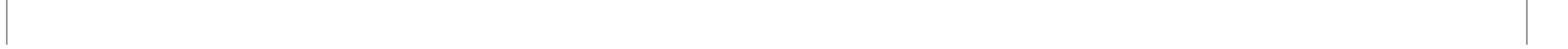

